Rasim M. Aliguliyev ${ }^{1}$, Rasim Sh. Mahmudov ${ }^{2}$

Institute of Information Technology of ANAS, Baku, Azerbaijan

DOI: $10.25045 /$ jpis.v07.i2.01

${ }^{1}$ secretary@iit.ab.az, ${ }^{2}$ rasimmahmudov@gmail.com

\title{
MULTIDISCIPLINARY SCIENTIFIC-THEORETICAL PROBLEMS OF FORMATION OF INFORMATION SOCIETY
}

The article explores and classifies multidisciplinary problems of the formation of information society. Various viewpoints, approaches, concepts on the theory of information society are analyzed. Activities, calls of international organizations on building information society are discussed. Areas of activity of influential scientific research centers of the world and journals dealing with multidisciplinary problems of information society are studied.

Keywords: information society, post-industrial society, multidisciplinary approach, information policy, information production, innovative activity, intellectual property.

\section{Introduction}

Formation and development of information society which is the modern phase of development of civilisation is based on information and communication technologies (ICT). Therefore, ICT determines the characteristics and development trends of information society. Today ICT experiences comprehensive and dynamic development process. All the achievements in the ICT sector are of practical importance and these achievements are applied to all the spheres of society in a flexible manner. Hence, the society and human life undergo severe, in some cases unexpected and unpredictable transformations period today. Thus, interrelated, interacting and interlinked change process is observed in sociopolitical, socio-economic, cultural spheres.

Since the information society is a production of complex changes appearing in all spheres of human activities, study of its scientific problems also requires multidisciplinary approach. In other words, scientific problems of information society requires coordinated studies on technology, economics, law, political science, philosophy, sociology, psychology, pedagogy, cultural studies, linguistics and other spheres.

The research of scientific problems of information society began in the early 70s. A range of scientific concepts, theories, and approaches were put forth during the past period. In those studies the information society are expounded from various aspects.

A number of international and regional organizations, as well as some agencies under the umbrella of the United Nations, apply the multidisciplinary approach while conducting researches, making reports, recommendations and concepts on information society. This approach of such organizations is also reflected in the national conceptual documents on the formation and development of information society.

There are influential scientific research centers in various countries of the world doing research on problems of information society. Researches conducted in such centers also feature the multidisciplinary character are, and complex approach on problems of information society is applied. Aforementioned scientific centers prefer international cooperation and carry out various projects in this direction. Simultaneously, a range of highly rated scientific journals on multidisciplinary problems of information society are being published.

The study and analysis of activities of relevant international and regional organizations, leading scientific centers and journals is of great significance for the institutions and researchers doing research on the problems of information society in our country.

\section{Scientific-theoretical viewpoints on information science}

Currently, there are lots of concepts characterizing information science. Authors of relevant concepts study most various aspects of information science. Some authors explore information science on the basis of multidisciplinary approach, i.e. from various scientific aspects, while others 
pay attention to its particular aspects. Those fundamental studies contain detailed scientifictheoretical analysis of new realities brought by ICT.

In the 70s, there was a convergence of two ideologies that emerged almost in the same period - "post-industrial society" and "information society" ideologies. After this, "post-industrial society" and "information society" ideologies were used synonymously. It is generally accepted that the term of "information society" was included to the terminology by a professor of Tokio Institute of Technology, Y.Hayashi. The term was used by K.Katoyam1, T.Umesso, F.Machlup afterwards.

In the reports, presented to the Japanese government with the title "Counters (outlines) of political aid to informatization of Japanese society" of the Council of Agricultural Structure (1969); "Information society plan" of the Institute of Utilizing Computer (1971); "Japanese information society: topic and approaches" of the Economic Planning Agency, general visions on the information society of the future were shaped: the development of computerization would provide access to reliable information resources for the people, and would set free them from routine by enabling the production to be highly automatized [4]. The general characteristics of information society were mentioned in such documents in the following form:

- development of good information sources and easy access for everyone

- high level of automation and robotization that release people from routine activities (intellectual types of activities as well)

- increasing the role of information in the value of the product.

According to the majority, relevant theoretical viewpoints are based on the "Post-industrial society" concept of the prominent American sociologist Daniel Bellin (1919-2011) [5]. The author puts forward that development of knowledge and technology has an influence on the progress of the society in this concept. He supposes that, in the post-industrial society, information-based intellectual technologies begin to replace machine technologies, the major political problem of this society is related to form, and characteristic of the government support towards science, not muscle strength and energy, but the information plays main role here. Followings are the main statements of the "Post-industrial society" concept:

- economic sphere: transition from production of industrial goods to production of services;

- employment sector: dominance of professionals and technicians class;

- major direction: leading role of theoretical knowledges as the source of innovations;

- future directions: control on technologies and technological values;

- process of making decisions: establishing new intellectual technologies.

In the D.Bellin's writings of the 70's. the idea of information society was not openly put forth, however, he considered the systematization of theoretical knowledge as the base principle of a new social order. D.Bell began to more profoundly influence the development of ICT society in the $80 \mathrm{~s}$, and since then, he became the supporter of information society concept. He began to consider this concept as the new phase of development of the post-industrial society concept [6].

Some scientists, however, consider that the idea of information society was firstly put forward by the prominent American scientist, founder of cybernetics Norbert Wiener (1894-1964). He wrote in the 50s that the exchange of information between machine and human, human and machine, and machine and machine would play a crucial role in the society in the future [7-8].

One of the authors of information society concept, Japanese scientist Yoneji Masuda (19051995) describes the bases of information society as following:

- new society will be based on computer technologies intended to replace or strengthen human mental activity;

- being leading sector of intellectual production economy which is created and spread by means of new telecommunication technologies, information revolution will become a new production force of the society; 
- the mass production of cognitive and systematized information, technologies and knowledge will be possible;

- the possibilities of cooperation and jointly problem solving will increase;

- intellectual production will become leading sector of the economy;

- "free society" will be the subject of the social activeness in the information society;

- major target of the new society will be the realization of "value of time".

American scientist Alvin Toffler (1928) made a significant contribution to the development of the information society concept. His trilogy of books titled "Future Shock", "The Third Wave" and "Powershift" were dedicated to this concept. "Future Shock" describes the influence of changes on people and institutions. In "The Third Wave", the directions of changes that affect society are analysed. The "Powershift" is dedicated to the challenges of governance during the change period [9-11].

A.Toffler defines economy in the information society as following:

- the role of exchange of information and knowledge increases;

- production of diverse ranged, but not mass goods, due to the new information technologies;

- the importance of traditional factors of production - labor, land, raw material and investment decreases;

- electronic information becomes the major exchange tool instead of traditional money;

- goods and services will become components of systems, which require the increase of volume of its standards. As a result, there will be struggle for the information containing those standards;

- sever bureaucratic workplaces will be replaced by flexible, temporary work alliances united around a single project;

- the number of diversity of forms of organization will increase, the exchange of information between them will become complicated;

- narrower specialization process will deepen in specialty fields, it will become difficult for workers with unique knowledges to replace each other;

- professionals. who could manage to unite imagination and knowledges with practical activities. will become the face of labor market;

- as a result of waste in one manufacturing process becoming raw materials for other manufacturing process, there will be abundance in the society, and this will be possible through computerization of relevant monitoring processes and deepening of scientific and ecological knowledge;

- manufacturers and consumers, separated as a result of industrial revolution, will reunite in the abundance producing cycle; consumer, besides money, will possess the market or economy related information that is significant for the effective production process. Eventually, the consumer will be able to speed up the production process.

- The process of production of abundance will be possible both on local and global scale. This process will be possible as a result of going beyond the national borders, with joint efforts of many states.

A.Toffler considers the time as one of the major values of the new civilization. According to him, rapid information flows and globalization lead to formation of "real-time economy". A.Toffler mentions individualization of production and people's preference to individualization in their activities, a sharp increase in the information exchange, preference to the self-governance in the political systems as main indicators of information society.

American scientist Manuel Castells (1942) doesn't mention the concept of "information society" in his writings. According to him, all societies used the information; therefore, all of them are information societies in fact. He names the new society as "network society" and defines age of information as an age of globalization. According to his views, collection, analysis and 
transmission of essential information are fundamental sources of productivity and power. $\mathrm{He}$ considers that the development of the 'informationalism' leads to the creation of network society and new economy. M.Castells writes in his book "The Information Age: Economy, Society and Culture" that the network connecting people, organizations and states will play a key role in the information age.

M.Castells defines the international division of labor in a new society as followings:

- producers of high value goods (information-based labor);

- producers of large-volume goods (not based high labor productivity);

- producers of raw materials (those with natural resources);

- producers of abundant goods (those using provided labor resources).

M. Castells shows the following characteristics of network enterprises: scope, interactivity, flexible governance, branding, consumer orientation. At the same time, he mentions that the transition of society into information age is not limited to technology and economy: "It also covers morality, cultures, ideas, as well as institutional and political structure of the society. It means the complete transformation of human life". M.Castell's the "Network society" concept arises from the recognition of information as the basis of the social structure. Thus, the author presents social structures as network structures that he accepts as new social structures. According to this views, operativeness, mobility and flexibility covering all areas of human life makes necessary the transition to network form of social structure: network system in the economy, interactive political system, single global information network - the Internet.

M.Castells defines the problems of network (information) society as following:

- problems associated with the internet management;

- restrictions on the use of the potential of the internet, digital inequality;

- problems associated with the development of information usage capability;

- problems associated with the transformation of labor relations;

- problems associated with an increase in the intensity of exploitation of natural resources;

- anxiety of losing control over man-made technologies;

French sociologist Alain Touraine (1925) calls information society as "programmed society". He mentions the changes in the production sector, government and management relations, as distinctive features of this society. He considers that trade in the agricultural society, production in the industrial society, communication in the information society are the main business sector [13].

American scientist Peter Drucker (1909-2005) contribute to the information society concept in his book titled "Post-capitalism society" published in 1995 [14]. In this book, he displayes own views on the current situation and development perspectives of the Western civilization. He characterizes the transition from industrial agriculture to the knowledge and information-based economy as prevalence of private capitalist ownership, formation of system of new values of modern human and transformation of idea of national statehood into the idea of global society due to the influence of globalization of economy and society. According to P.Drucker, traditional factors of production - land, labor and investment are not eliminated, simply passed into the background. In his opinion, traditional resources of production (land, labor and investment) can be easily obtained by possessing necessary knowledge. He states that power and control are gradually passed from the investment owners to the owners of information and knowledge, using technologies of those resources.

American economist Fritz Machlup (1902-1983) in 1962, for the first in USA economy, differentiated "production and expansion of knowledge" sphere, and introduced the term "economy of knowledge" to the scientific circulation [15].

According to German sociologist Tom Stoner (1927-1999), information society is the age of abundance; everybody will become aristocratic and philosopher [16]. According to him, since 
the food concerns of the people ended up at the end of industrial society, the end of the communicative society will eliminate the concerns about the financial needs. "As industrial society eliminated slavery, famine and epidemics, information society will wipe out authoritarianism, war and antagonism. The first time in the history, our speed of problem solving will exceed the speed of their creation". T.Stoner considers that information can be accumulated like a capital and kept for future use. According to his views, national information resources will become the greatest potential wealth in the information society and therefore, first of all, attention should be paid to the information economy.

Russian scientist Vladislav Inozemtsev (1968) considers that information technologies and resources lead us to "post-economic society" and here, creative activity, which is selfrealization of personality, will replace the labor activity motivated from the economic [ers[ectives [17].

American politician Zbigniew Brzezinski (1928) puts forward "technetronic society" concept [1]. In his book titled "Between Two Ages: America's Role in the Technetronic Era", he discusses that information society will turn into technetronic society. He considers that technetronic society is the formation of new cultural, psychological, social and economical relations as a result of developments in technology and electronics, particularly in computer and communication sectors.

Canadian scientist Marshall McLuhan (1911-1979) is considered as one of the classics in the sphere of the mass communications theory. He considers the information technologies as the key factor affecting formation of socio-economic basis of new society. M.McLuhan states that electricity turns the earth into the global village through telecommunications, mass media and computers. According to him, mass communications become the part of the modern society and at the same time, have special power over it.

American sociologist Herbert Schiller (1919-2000) deems that the interests of corporate capitalism dominate in the information sphere. According to his viewpoints, the development of information processes and technologies, first of all, serves for the interest of private business, not of the whole society. H.Schiller claims that there are, above all, traces of cooperative investment on the information technologies, all other interests are on the background.

The views of another Russian scientist Nikita Moiseyev (1917-2000) on information society are of great importance. In his opinion, without providing free access to information, it is impossible to talk about information society - collective intelligence building globally. He considers that the second important factor for collective intelligence building is the people's intention to share their knowledge. N.Moiseyev put forward a "collective wisdom" concept. He understands the "collective wisdom" as a system connecting people with information links. According to his views, the collective wisdom is the special information system which not only gathers and passes information, but also analyses and draws conclusion and unifies them in a special form. N.Moiseyev considers that, when the collective wisdom will have the features to impalement such functions, the mankind will take a step to the information society.

English sociologist Anthony Giddens (1938) doesn't accept the "information society" concept. He considers that the society has always been informed from the very begining, not in the modern era. In his opinion, the increase in the value of information in modern era doesn't mean formation of a new society. According to the A.Gidden's theory, people provide their financial and social life on the basis of abstract knowledge acquired from the mass media and educational institutions. People choose their lifestyle and model of behavior in the circumstance of having access to any information. However, in the developed societies, choices are not dependent on territorial, traditional and other factors [1].

Mark Poster (1941), a prominent representative of postmodernism, attaches great importance to the role of the Internet in the information society [1]. He considers that globalization process occurring under the influence of the Internet breaks down the nation states, 
the Internet gives individuals more freedoms than the citizenship, the Internet saves the citizen from tyranny of nation state and transforms to a free person. Such notions of M.Poster are considered threatening towards national interests, as these notions contain calls for civil disobedience.

Italian scientist Gianni Vattimo (1936) studies information society from the aspect of cultural studies[21]. He considers the increase in the number and scope of the mass media as an important factor in the modern society. He notes that rapid increase in the number of broadcasting and cable television destroys the people's trust for the realities of new world. The mass media brings alternative realities to society, increases the present realities and people become forced to live amid different cultures.

German scientist Jurgen Habermas (1929) had conducted research on information management and manipulative technologies sectors [22]. He put forward the "Public sphere (Information sphere)" concept. Although the author agrees that the importance of information in the society increased, he doesn't accept the idea the idea of creation of information society. J.Habermas shows the following features of crisis in the public information sphere:

- information converts into goods;

- information waste is increasing;

- public institutions (libraries, museums, galleries, etc.) become commercial;

- persuasion is observed in politics and advertising instead of discussion.

The major characteristics of information society are more broadly discussed in the papers of Canadian scientist Don Tapscott (1947) titled "Electronic-digital society" [23]:

Knowledge orientation. Intellectual labor becomes the basis of building material values and creation of revenue. Knowledge becomes the component of the good. Knowledge-oriented technical devices begin to be widely used. Information-control system is transformed into knowledges system.

Digital presentation form of objects. Documents turn into electron-digital form. The communication between people takes the form of units and zeros. The transition from analog techniques into electronic-digital techniques occurs (communication, data recording systems, copying).

Virtual characteristic. Physical objects and organizations become virtual. Virtual shops, warehouses, offices and brigades emerge. Data virtualization occurs and "virtual reality systems" are formed.

Molecular structure. Administrative-team hierarchy comes to an end. Individual workers and teams gain the opportunity of freedom of activity and creating goods. The components, which are multifunctional and stipulated for multiple uses, are created.

Integration. Internetworking interaction. A new type of enterprise - is a network element. Independent module organizations, which make up single service and production network, arise. Building material values, trade, social life is based on commonly used global infrastructure.

Elimination of mediators. As a result of removal of agents, brokering services, wholesale centers from the economic activity direct relations between manufacturers and consumers arise.

Convergence. The convergence of major sectors of economy and organizational structures occurs.

Innovative environment. Innovation becomes the driving force of economic activity and success. Human imagination act as the main source of values instead of traditional success factors like access to raw material, productivity, scale and the value of labor force.

Transformation of "manufacturer-consumer" relations. The borders between manufacturers and consumers wipe out. Knowledge and information of consumers are used in the production of goods, as well as in the use of information systems and program productions. Consumer could watch the creation of the desired product and make changes to it. 
Dynamism. New society acts in the real time. Trade becomes electronic, communication is momentarily realized, and direct control and management provide the real picture of the process with all of its necessary parameters.

Global scale. Knowledges are beyond borders. The economy is becoming globalized. Building interaction and cooperation is not limited to time and place. Work can be carried out from everywhere, from home as well. Interdependence of states is increasing.

The existence of contradictions. Mass social conflict is arising between working employees and workers with needless knowledge, dismissed workers, educated and non-educated, the ones with access to information highway and the ones without.

\section{International organizations dealing with multidisciplinary problems of information society.}

The necessity of deep understanding of the most radical changes in the history of the civilization occurred as a result of rapid development of ICT and its influence on all spheres of human activity and making future-oriented decisions in the new situation has led to the formation of a number of influential international and regional organizations in this sector. Approaches of those organizations on the solving of problems of information society are of multidisciplinary (complex view) character.

The reason for putting forward the idea of holding World Summit on the Information Society, WSIS in 2003 (Geneva) and in 2005 (Tunis) stemmed namely from this necessity. $[24,25]$.

The "Declaration of Principles" adopted at the Geneva Summit defines various conceptual notions on information society and common direction of political efforts of different states. The document also contains a set of philosophical, social, political, culturological and technological notions on information society.

In the "Tunis Commitment", adopted at the Tunis summit, it is declared that building information society is based on human interests, principles of the Charter of the United Nations, the Universal Declaration of Human Rights, and it is reaffirmed that freedom of speech and information, ideas and knowledge are of great importance for the information society. The key role of the use of ICT in enterprises in the economic development is also noted, and the necessity of struggle against emerging threats as a result of the use of ICT is emphasized. At the same time, the document takes the commitment the implementation of relevant monitoring and evaluation in order to define the level of development of the information society and to eliminate the digital differences.

"Tunis Agenda for Information Society" contains the issues regarding identifying financial mechanisms to overcome the digital differences and increasing the focus on the Internet regulation issues.

In 2014, “WSIS+10”Summit was held in Geneva for analysis of the activity on implementation of the decisions of the World Summit on the Information Society held in two phases in 2003-2005 [26]. The concept of action for the post-2015 period of "WSIS + 10" was approved at the Summit. At the concept, the participating countries are recommended to strengthen the activity in the following directions:

- role of government bodies and all other interested parties in order to use ICT for development;

- information and communication infrastructure;

- information and knowledge accessibility;

- creation of potential;

- $\quad$ strengthening reliance and security in the use of ICT;

- effective environment

- ICT applications: benefits in all aspects of life (e-government, e-business; e-education, e-health, e-employment, e-ecology, e-agriculture, e-science); 
- cultural diversity and cultural identity, linguistic diversity and local content;

- mass media

- ethical aspects of the information society

- international and regional cooperation.

The United Nations Development Programme (UNDP) operates in the direction of creating favorable conditions for the development of ICT in developing countries [27]. The agency finances local, regional and international programs on the development of ICT by means of a special fund; Deals with the defence of the international law of organizations operating in the ICT sector; Makes efforts for expansion of international relations in the ICT sector; Makes recommendations and strategies for the implementation of programs on ICT.

UNESCO, the United Nations' agency specialized in the scientific, educational and cultural issues, to deliver its recommendations on challenges of the development of the information society $[25,28]$. The agency acts with knowledge society concept instead of the information society concept. UNESCO considers that, for building fair information society, first of all, efforts should be made to explore and to solve the following problems:

1. ICT and gender issues;

2. Cultural and linguistic diversity;

3. Freedom of expression and the press

4. The problems of ICT and disabled persons

5. The problems of information ethics and accessibility of knowledge and information for everybody.

UN's other specialized agency - the International Telecommunications Union (ITU), deals with the following problems related to the formation of the infrastructure of the information society [29]:

- equal access to ICT;

- building broadband Internet network in order to solve socio-economic development issues;

- use of ICT to eliminate the consequences of the climate change;

- ensuring the security in cyberspace, including cybercrime and spam spread issues;

- building reliance associated with the use of ICT;

- elimination of information inequality;

- use of ICT to ensure the safety of life;

- creation of new generation networks.

Research works of ITU are carried out within activity of three sectors: the standardization sector, telecommunications sector and the development sector. Each sector has several research groups involved in the study of the specific issues related to the respective problem. In general, studies carried out with the support of ITU mainly have the application nature and focused principally on the development of infrastructure.

United Nations Conference on Trade and Development (UNCTAD), within its mandate, publishes a series of articles on different aspects the use of ICT [30].

Organization for Economic Cooperation and Development (OECD), within the framework of its activities, deals with the use of ICT for the development purpose [31]. Recently, the organization carried out studies in the following topics: information security (inviolability of private life, digital identity problems, the spread of spam); stimulation of innovations; information society infrastructure (critical infrastructure, broadband technologies, new generation technologies); "clean" technologies and "smart" software; digital content (including piracy issues); increase of accessibility of the official information and effective usage of it; information economy (Internet economy, the competition in the telecommunications sector, consumer protection, support and training); e-government (user-oriented services); e-commerce; information industry (including employment in the ICT sector); mass media. 
The World Information Technology and Services Alliance (WITSA) incorporates 46 national associations in the ICT sector [32]. Alliance members make up $90 \%$ of the global ICT market. The main mission of this organization includes strengthening the international competition in the ICT sector, protecting intellectual property rights, unifying the efforts of states in order to ensure the information security, eliminating the differences in the level of education and qualifications on ICT between countries, ensuring the sustainable development of the Internet and e-commerce.

In 2010, "Digital Diary for Europe" was adopted by the European Commission [33]. The document has a special section devoted to researches and innovations. European Commission prepared the development strategy until 2020 for relevant researches and innovations in order to strengthen the innovative impact of ICT as goods and services on the european markets. The goals and objectives of the strategy focus on improving the living standards and meeting social needs. The main statement of the strategy are related to normative legal (certification, standardization, etc.) and organizational (public-private sector partnerships for building "road maps" on technological sector, establishment of knowledge transfer, as well as ensuring open access to scientific information and publications created at the expense of budget funds etc.) issues.

\section{Influential scientific research centers dealing with multidisciplinary problems of the information society}

Multidisciplinary scientific problems of the information society are one of the priority areas of the world science. In many countries of the world, there are special scientific centers conducting research in this direction. Some of these centers possess international or regional status. In other words, scientific projects covering different countries are carried out and research scientists and experts from different countries are involved in these centers.

Employees of one of such centers European Network for Information Society Research, $E N I R$, are doing important work in the Information Society sector [34]. The Network incorporates more than 100 organizations from European countries, as well as Brazil, China, Mexico, the United States, Tunisia, Switzerland and Japan. The major users of the network include the Commission of the European Communities, national and regional administrative bodies, various business associations. Among the main topics of research in the areas of social importance - health, business, public administration, employment, ensuring the active participation of citizens in public life, the disabled and the elderly in the service sector, education - application of ICT have a special significance. Studies of participants cover areas such as use of indicators, market research, citizenorientation provision of online public services, employment model for older people, the impact of ICT in various application spheres, assessment of strategic and program documents and search and analysis of advanced practices.

European Cooperation in Science and Technology, COST, also conducts research in the field of development and application of ICT [35]. This organization coordinates the activities funded by the states in several European countries as an intergovernmental structure. Also the organization ensures international cooperation of national scientific research institutes, universities and business organizations of Europe. COST's main research directions include:

- biomedicine and molecular biology;

- food and agriculture;

- forestry (products and services);

- materials, physics and nanotechnologies;

- chemistry, molecular research and technologies;

- management of earth and environmental sciences;

- information and communication technologies, transport and urban development;

- citizens, society, culture and health. 
European Research Coordination Agency, EUREKA, currently covers 39 countries [36]. The objective of the establishment of EUREKA is to eliminate lag of Europe from the US and Japan in scientific and technical spheres. This network contributes to the development of international market oriented research and innovations by supporting small, medium and large businesses, universities and research institutions. The network participants are united in clusters on long-term basis and principles of "government-business partnership". New products and services which promote the economic growth and social development of Europe are taken to the market through EUREKA network. Results of the relevant research projects have been used to create devices and technologies for monitoring of GSM technologies, mobile communication, navigation systems, smart cards supporting mobile and e-commerce, the software of the film industry, environmental pollution.

A research institution in Europe called Future of Identity in the Information Society, FIDIS, - the network of academic institutions and organizations which is specialized in study of identity problem in the information society [37]. This network studies problems of submission of personal data in electronic form, including various identification methods, anonymity and pseudonimity problems, the use of numerous identities and its goals, profiling, high-tech IDs, compliance of identifiers, inviolability of private life and the consequences of its violation etc.

Information Society Research Group's, School of Information \& Library Studies, University College Dublin activity is also very efficient [38]. The research group's interests include the spheres as information policy, e-government, the impact of technology and the Internet on public relations and cultural models, social investment of the information society, philosophical aspects of the information and communication, ethnographic aspects of the activities of organizations and information systems, information requirements of societies.

Yale University law school, the United States, is engaged in the study of the problems of the information society. The relevant research project of the school is called: "The Information Society Project: Memes (meme - is a cultural information unit), Genes and Bits at the Yale Law School" [39]. Within the project, the studies on acquiring knowledge, online civil freedoms, eeducation, reforms in the field of intellectual property and innovations etc. are supported, the lessons are held, ideas are formed and spread.

Alexander von Humboldt Institute for Internet and Society (HIIG) at the University of Berlin is studies the dynamic relationship between the Internet and society [40]. The aim is to study the interaction of the socio-cultural, legal, economic and technical norms. The Institute carries out joint research projects at national and international levels. HIIG puts forward new ideas and suggestions related to the opportunities and challenges of the information society through fundamental and empirical studies.

Berkman Center for Internet \& Society (BCIS), is research institute operating under the Harvard University [41]. The main mission of the law-focused center includes the study of the problems related to characteristics of cyberspace - trends, dynamics, norms and standards. Issues of inviolability of private life, protection of intellectual property, management of content and ecommerce are also studied here. Research projects as "Digital media law", "Internet and democracy" were carried out at the center. The Center's Internet portal offer opportunities for teachers and students, entrepreneurs, lawyers, programmers to attend the lectures and hold free discussions. BCIS also sponsors scientific conferences and other meetings.

Canadian Internet Policy and Public Interest Clinic (CIPPIC), operates as a Legal Clinic at the University of Ottawa [42]. The main objective of the research center is to give scientific support for the country to fair and balanced policy-making process on technologies. In other words, the center holds a mission to represent the interests of the society on different issues that arise at the intersection of technologies and legal system in the country. CIPPIC, on a regular basis, is represented as expert group at the Canadian parliamentary committees, as well as various courts. In addition, the organization is actively involved in the activities of the Internet 
Governance Forum. The research center offers consulting services to individuals and legal entities, carries out public awareness campaigns on various legal issues, as well as is engaged in educational activities.

The Centre for Internet and Society (CIS), operating in India, is a non-profit organization doing multidisciplinary researches on the Internet and other digital technologies [43]. Directions of activity of the center cover the areas such as accessibility of digital knowledge for citizens, protection of intellectual property rights, Internet regulation, telecommunications reforms digital privacy and cyber security. CIS, by means of the Internet and digital media technologies, also pays special attention to the study of social and cultural processes, transformations taking place in the society.

Center for Internet and Society (CIS) at the Stanford Law School, consists of academics, legislators, students, programmers and security experts [44]. The researches on the legal aspects of technology, including ensuring freedom of speech, inviolability of private life and application of innovation are carried out at the center. Law students and the general public are provided with the analysis of political issues arising at the intersection of law, technology and public interests, as well as with relevant educational materials here. The center also finances a number of public events, as well as scientific conferences and seminars.

Nexa (means "related things" in Latin language) Center for Internet and Society of the Polytechnic University of Turin (Italy) is established at the management and computer engineering department [45]. Operating as a scientific research institution, center studies the information society and the Internet on the basis of multidisciplinary approach - technological, legal and economic aspects. The research center jointly works with the European Commission, national and local authorities, businesses and other organizations. The main objective of the center includes the study of the main factors that characterize the Internet, their dynamic and impact on society.

Oxford Internet Institute (OII) is established at the University of Oxford in order to explore the social consequences of the Internet [46]. OII covers various scientific fields, including politology, sociology, geography, economics, physics and philosophy. A wide range of the methods and sources of information are used in the institute to study the Internet environment. Books and journals published by OII present research results on the topics such as inviolability and security of private life, e-government and e-democracy, virtual economy, information ethics, "smart city", online games, big data, Internet geography, digital restrictions, digital humanities, Wikipedia.

Taiwan Institute for Information Industry (TIII) is established in Taiwan, in order to provide scientific support for formation of the information society, innovative application of information technologies, development of the knowledge economy [47]. The Institute also has the functions of scientific support and coordination between the Ministry of Economy and leading instituions on ICT for economic development of the country. The institution's activity on Taiwan's achievement of global competitiveness ability in ICT industry is highly appreciated. The departments of "smart" network systems, innovative applications and services, data analytics and cyber security, e-education operate within TIII.

Information Society Center in Berkeley (ISCB) established in the USA, is engaged in the study of social impacts of the last information revolution [48]. The head of the research council of the Center is prominent researcher of the information society M.Castels. The main activity of the research center includes:

- the problems of the global information society and their solution models;

- use of ICT in the social sphere;

- increase of equal social opportunities.

Multidisciplinary researches on the problems of information security and confidentiality which became pressing issue due to the development of information technologies are conducted 
at the Center for Information, Society and Policy (CISPA) based in Chicago [49]. The center unites experience of computer science scientists, psychologists, lawyers, business experts and others.

Korea Information Society Development Institute (KISDI) deals with the issues of application of ICT in the economy [50]. Being the leading think tank consisting of prominent experts from South Korea, KISDI puts efforts to achieve positive changes, opportunities and achievements in the life of the country. This institute plays an important role in turning in South Korea becoming a leading country in ICT industry in the world. The institute focused its research efforts on the future development of the information society, informatization, creative economy, telecommunications sector and electronic media of the country.

\section{Prestigious scientific journals dedicated to the multidisciplinary problems of the information society}

Currently, a range of prestigious journals, dedicated to the multidisciplinary problems of the information society, are published in different countries of the world. The results of theoretical and empirical researches on various aspects of the information society are published in such journals.

The first such journal was established in 1981 in the United States. In the journal titled "The Information Society" the articles on discussions about understanding and analysis of the impact of ICT in the life of society, conceptual and strategic documents, methodological approaches, different trends (social transformations, changes in cultural features, etc.) related to the relevant fields are published [51].

One of the Springer's publications, the "Universal Access in the Information Society" journal, publishes the results of scientific-research works on designing, development, working, use and impacts of information society technologies, as well as standardization, policy and other nontechnological issues facilitating and expanding common availability. The results of theoretical, methodological and empirical studies are preferred in the journal [52].

Another journal published in the Springer - "AI \& Society" is also multidisciplinary. The journal publishes research results of management, security, cultural, social, economic, ethical, philosophical problems of the application of new technologies [53].

Russian-published "Информационное общество" (Information Society) journal is a periodical scientific publication specializing in complex problems of the development of the information society [54]. $40 \%$ of the articles published in this journal are dedicated to egovernment, $20 \%$ to e-education, $8 \%$ to e-health, $8 \%$ to the use of the Internet.

"Journal of Law and Policy for the Information Society" published in the UK is a periodic publication specialized in multidisciplinary problems of the information society [55]. The journal includes the headings such as intellectual property protection, e-democracy, cybersecurity, inviolability of private life.

British "Journal of Information, Communication and Ethics in Society" is a periodic publication presenting the results of researches on multidisciplinary problems related to the information society [56]. The magazine introduces the articles on the study of social and ethical issues such as planning, development, implementation and use of new mass media and information and communication technologies. The audience of the publication consists of scientists from anthropology, business, computer science, journalism, philosophy, political science, psychology and sociology spheres.

India's scientific publication titled "International Journal of Information Library and Society" publishes articles on the role of libraries in the information society, ensuring citizens' rights to information, pressing problems of e-libraries [57]. The scope of the topics covered by the periodic publication is very broad: data protection and copyright, e-libraries, formalizing e-documents, e-resources, new technologies, library and the society, library 2.0., scientific libraries, e-library management etc. 


\section{Conclusion}

Despite the certain contradiction in the approaches provided by the authors of respective scientific-theoretical concepts, the researchers unanimously agree on one issue that information society has period of radical qualitative changes, which serve for the rapid development of the humanity. All the relevant studies are focused on the perception of the system of values and new relationships established at this period, and leaned towards the exploration of ways for solving the problems. The efforts and calls of international organizations serve to support the establishment of the ideology of information society, importance of which is scientifically approved in the world, from organizational and methodological aspects.

Analysis of the well-known scientific-theoretical concepts, pleas of international organizations, activities of leading scientific research centers and journals show that solving the problems of this sector requires a complex approach, multidisciplinary scientific methodology. Because, the information society is a virtual alternative to the real world. The process of virtualization covers all areas interacting with one another.

Based on the respective analysis, scientific-theoretical problems of the formation of the information society can be grouped as follows:

Technological: advantages of the use of ICT in all spheres of human activity and its innovations; the formation of the infrastructure of the information society (critical infrastructure, broadband Internet development, the creation of next-generation networks, etc.); "Smart", "green" and other new technologies, stimulation of the development of data analytics, ensuring information security, the use of valid identification methods;

Legal: legal aspects of ICT; ICT standardization and certification issues; ensuring the rights of citizens to information; the legal regulation of the Internet; fight against cybercrime; intellectual property and protection of consumer rights;

Economic: the transformation of traditional economic relations; the globalization of the economy; the increasing role of information factor in the production and economy; the formation of information and knowledge economy; stimulation of innovativeness and creativity in the new economy; the development of e-commerce; changes in the nature of labor, the creation of new forms of trade;

Political: new public management concepts; concepts and models of building the information society; information policy; the concept of e-government; public sector-private sector-civil society cooperation in the information society; digital democracy; the role of freedom of speech in ensuring human rights and political processes; the manipulation of information; international cooperation in the field of information society;

Social: the formation of a new system of values of human and society; the structure, features, development methods and philosophical understanding of the new society; processes which act as an important stimulator of changes in the quality of life; virtual reality features; social networks and social media; digital divide; the importance of social investment; to ensure the interests of marginal groups in the information society;

Locational: globalization processes occurring as a result of the spread of information and communication networks and its positive and negative aspects;

Psychological: changes in social and individual consciousness, feelings, and moods with the impact of ICT, addiction to information;

Culturological: culturological value of information; the increase in informativeness of modern cultural sphere; the expansion of the role an influence of the mass media in modern society; information culture; protection of cultural and linguistic diversity. 


\section{References}

1. Webster F. Theories of the Information Society, Routledge, 2007, 312 p.

2. Manakova I.Y. Methodological aspects of the study of post-industrial society // Bulletin of Voronezh State University. Series: Philosophy, 2011, No1, pp. 74-87.

3. Kumar K. From Post-Industrial to Post-Modern Society: New Theories of the Contemporary World, John Wiley \& Sons, 2009, 304 p.

4. Bell D. The Coming of Post-industrial Society: A Venture in Social Forecasting, Basic Books, 1976, $507 \mathrm{p}$.

5. Bell D. Social framework of the information society // New technocratic wave in the West, Moscow, Progress, 1986, pp. 330-342.

6. Litvak N.V. About the classification of the information society // Sociological researches, 2010, No8 pp. 3-12.

7. Wiener I. Cybernetics, or Control and Communication in the Animals and the Machines, Moscow, Soviet Radio, 1968, 328 p.

8. Masuda Y. The Information Society as Post-industrial Society, Washington, 1981, $286 \mathrm{p}$.

9. Toffler A., Toffler H. Creating a New Civilization: The Politics of The Third Wave, Atlanta, Turner Publishing, 1995, 112 p.

10. Toffler E. Future Shock, AST, 2008, 558 p.

11. Toffler E. Metamorphoses of power: knowledge, wealth and power on the threshold of the XXI century, AST, 2009, 668 p.

12. Castells M. The Rise of The Network Society: The Information Age: Economy, Society and Culture, Wiley, 2000, $624 \mathrm{c}$.

13. Clark J., Diani M. Alain Touraine, Psychology Press, 1996, 381 p.

14. Drucker P. Post-Capitalist Society, Routledge, 2012, 212 p.

15. Machlup F. Production and dissemination of knowledge in the United States, Moscow, Progress, 1966, $462 \mathrm{p}$.

16. Stonier T. The Wealth of Information: A Profile of the Post-industrial Economy, Thames Methuen, 1983, $224 \mathrm{p}$.

17. Gordon W. T. Marshall McLuhan - Escape Into Understanding: A Biography, Gingko Press, Incorporated, 2004, $465 \mathrm{p}$.

18. Inozemtsev V.L. Beyond the economic society: postindustrial. Theory and postecon. Trends in the modern world, M., Academia: Science, 1998, 639 p.

19. Salvaggio J.L. The Information Society: Economic, Social, and Structural Issues, Routledge, 2013, $152 \mathrm{p}$.

20. Moisev N.N. The fate of civilization. The path of mind, M. 2000, 224 p.

21. Vattimo G. Transparent Society, M., Logos, 2002, 128 p.

22. Habermas J. The Structural Transformation of the Public Sphere: An Inquiry Into a Category of Bourgeois Society, MIT Press, 1991, 301 p.

23. Tapscott D. Electronic digital society, M., Refl-book, 1999, 432 p.

24. http://www.publicadministration.un.org/wsis10

25. Chernov A.A . The formation of a global information: problems and prospects, M., "Dashkov and $\mathrm{K}^{\prime \prime}, 2003,232 \mathrm{p}$.

26. ITU, Outcome WSIS+10, Ceneva, 2014, 50 p.

27. http://www.sdnp.undp.org/it4dev

28. http://en.unesco.org/themes/building-knowledge-societies

29. http://www.itu.int/en/Pages/default.aspx

30. http://unctad.org/en/Pages/Home.aspx

31. http://www.oecd.org

32. www.witsa.org

33. http://ec.europa.eu/index_en.htm 
34. http://www.enir.org

35. http://www.cost.eu

36. http://www.eurekanetwork.org

37. http://www.fidis.net

38. http://www.ucd.ie/ics/research/informationandsociety

39. https://www.law.yale.edu

40. http://www.hiig.de/en

41. https://cyber.law.harvard.edu

42. https://cippic.ca

43. http://cis-india.org

44. http://cyberlaw.stanford.edu

45. https://nexa.polito.it/noc

46. http://www.oii.ox.ac.uk

47. http://web.iii.org.tw

48. http://www1.icsi.berkeley.edu/BCIS

49. https://www.kentlaw.iit.edu/institutes-centers/center-for-information-society-and-policy

50. http://kisdi.re.kr/kisdi/jsp/fp/eng/about/KE_31000.jsp

51. http://www.indiana.edu/ tisj/index.htm

52. http://www.springer.com/computer/hci/journal/10209

53. http://www.springer.com/computer/ai/journal/146

54. http://www.infosoc.iis.ru

55. http://www.is-journal.org

56. http://www.emeraldinsight.com/journal/jices

57. http://www.publishingindia.com/ijils 